\title{
Modelling the impacts of current patterns of urban form expansion in Kuwait with the use of ABM and GIS
}

\author{
$\underline{\text { N. Alghais }}^{\text {a }}$ and D. Pullar ${ }^{\text {a }}$ \\ a School of Geography, Planning \& Environmental Management (GPEM), The University of Queensland
}

Email:n.alghais@uq.edu.au

\begin{abstract}
During the last six decades Kuwait City has experienced a rapid and unpreceded population growth with only a small increase in the respective urban area. This is largely due to the discovery of oil and arrival of thousands of new immigrants. The alarming rise in the urban density has caused issues for the residents' lifestyle, the economy and the environment. Historically, urban planning decisions in Kuwait were based on a series of "Master Plans" implemented by the government. Generally the plans, the last of which was formulated in 1997, promoted concentrated high density development in the city's Central Business District (CBD), and resulted into a low density urban sprawl expanding outwards in a radial fashion.

A significant disadvantage of this top-down approach is the lack of inclusion of the citizens' suggestions and opinions, unlike similar expansion and planning policies in Western cities. Furthermore, the plans failed to incorporate measures to successfully accommodate the increase of vehicles and high traffic density, resulting into severe congestion issues and commuting times. Additionally, land development constraints set by the plans in combination with the increase of Kuwaiti citizens eligible to apply for housing welfare, caused a considerable increase of waiting times for receiving the government grants and drove property prices to levels out of reach for the majority of population. Pressure caused by these matters, has caused several protests in Kuwait, making the analysis of the impacts of current patterns of urban form expansion critical.
\end{abstract}

To predict the future effects of the continuation of the existing pattern of urban growth in Kuwait on congestion and housing shortage a series of simulations based on Agent Based Modelling (ABM) and Geographical Information Systems (GIS) is proposed. ABM provides a mean to evaluate decisions by different citizen groups on their settlement patterns and interactions with other groups, such as the developers and the government. The simulations are able to receive and overlay GIS data inputs related to land use, transport networks, and demographics. The simulations have a horizon of 35 years (up to 2050).

This paper discusses the rationale, design methodology and parameterisation of the ABM and the agent groups that constitute the framework. The base set of rules governing the behaviour of the agent groups was derived after analysing real data from historical Kuwait archives. The analysis findings are outlined in this paper. The findings imply that there are significant inherent correlations between urban form expansion and urban transportation quality as well as land use distribution.

Using the historical trends as a guide for future expansion and assuming linear development along the current transportation networks it is possible to obtain five yearly predictions for the future state of:

- Land use and development ratio

- Accessibility to transportation networks, work, shopping centres, services and infrastructure

- Population growth, distribution patterns and density.

The analysis of the simulation outputs will enable the generation of a set of predictions for the impacts on congestion and housing shortage in Kuwait. The outputs of the model will also enable the evaluation of the centroid urban form expansion and can form a basis for reference for developing alternative urban planning and expansion policies not just in Kuwait, but in other modern cities especially ones that experienced rapid radial growth around their $\mathrm{CBD}$.

The proposed model with appropriate modifications will also be applied for simulating two alternative scenarios of urban form expansion in Kuwait in future work, hence allowing a quantitative comparison of urban planning strategies.

Keywords: Agent based modeling (ABM), urban form, Geographical Information Systems (GIS), congestion, land use 


\section{INTRODUCTION}

Arab gulf metropolises such as Kuwait, Doha and Dubai, have experienced complete transformation and change of their urban landscape in the last half of the 20th century. In Kuwait, the discovery of oil became the main driving force behind the rapid urbanisation, as well as the architectural and social reformation or "Alnahda" Age in Kuwait as stated by Al Nakib (2013). This Age was accompanied by a rapid population growth due to the arrival of thousands of new immigrants for working in new projects oil and infrastructure related projects. The population growth over the last 60 years can be seen in figure 1.

Historically, urban planning decisions in Kuwait were based on a series of "Master Plans". The first Master Plan was out in 1952 and aimed to transform Kuwait from a small port town to a modern city. Provision was made for an efficient road network, government

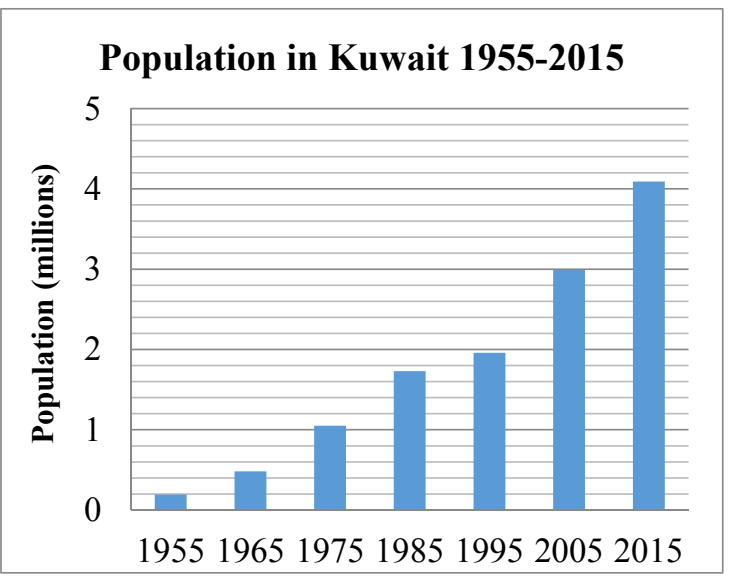

Figure 1. Kuwait population growth since 1955 (United Nations, 2015). buildings, industries, commercial centres, Kuwait CBD redesign and the development of new housing areas and facilities. Government and corporate buildings were concentrated in the CBD and connected to the new suburbs by a system of ring and radial roads. The second Master Plan was developed in 1970 and revised in 1977 and in 1983. It was established to accommodate the large numbers of new immigrants causing the doubling of population between 1965 and 1975. This Plan included nationwide planning, provision of new residential areas, environmentally friendly and sustainable improvements of the urban environment and redevelopment of the transportation system. As with the first Master Plan, the approach of the second Plan was based on low density urban development with focus on the CBD. The third Master Plan was established in 1997 and aimed to account for the effects of population growth by 2015 that was expected to reach 3.8 million.

All Master Plans promoted a construction boom, which in turn resulted in an unprecedented expansion of the developed urban area. However, this was a relatively small increase compared to the population growth. Kuwait has a population density of roughly 230 people $/ \mathrm{km}^{2}$, and an urban density of 2800 people $/ \mathrm{km}^{2}$. More than $99 \%$ of the population resides in urban areas which account for $8 \%$ of the total area of Kuwait. The alarmingly high urban density has caused various detrimental issues for the residents' lifestyle, the economy and the environment. In Kuwait, most serious problems such as congestion, deterioration of commuting times, rising real estate prices and pressure on public services are accredited to high urban density.

The strategy Kuwait's government had used in planning since the early fifties was a top-down approach as there was not any public participation. The notion that urban planning and development should be facilitated by the citizens' ideas, habits and needs has been supported by several studies, such as Al-Nakib (2014), Belkina (2014) and Ruming (2014). According to Contin et al. (2014) in most Western cities, citizens are able to participate in processes that govern urban growth and development via committees and in public forums. On the other hand, in Middle Eastern cities citizens are rarely allowed to express their personal views and suggestions on urban planning as concluded by Hamouche (2004). The recent events known as the 'Arab Spring' illustrated that an increasing part of the population in Middle Eastern cities was dissatisfied with a variety of policies - including the urban growth management by excluding public participation from the process of planning.

Another issue resulting from the three master plans according to Alshalfan (2013) is a high car dependency. The total number of vehicles has increased significantly since 2000, and reached more than 1.6 million registered vehicles in 2012 according to the Kuwait Central Statistical Bureau (2012). The policy makers are planning to build $700 \mathrm{~km}$ of new roads during the next 5 years according to UNDP (2009). Nevertheless, Kuwait ranks as number 4 in the world in the list of countries with the highest number of registered vehicles per kilometre of road. Besides delays and wasting time with dire economic consequences ( $3 \%$ of GDP), congestion in Kuwait has additional negative impacts, such as wasting fuel, increasing air pollution, hampering emergency vehicle access to congested areas, higher rates of accidents (as seen in figure 2) and increasing the difficulty of forecasting travel time according to UNDP (2009). Ehrlich (2003) concluded that accident frequency increases with high congestion levels (due to more vehicles being on the roads). 


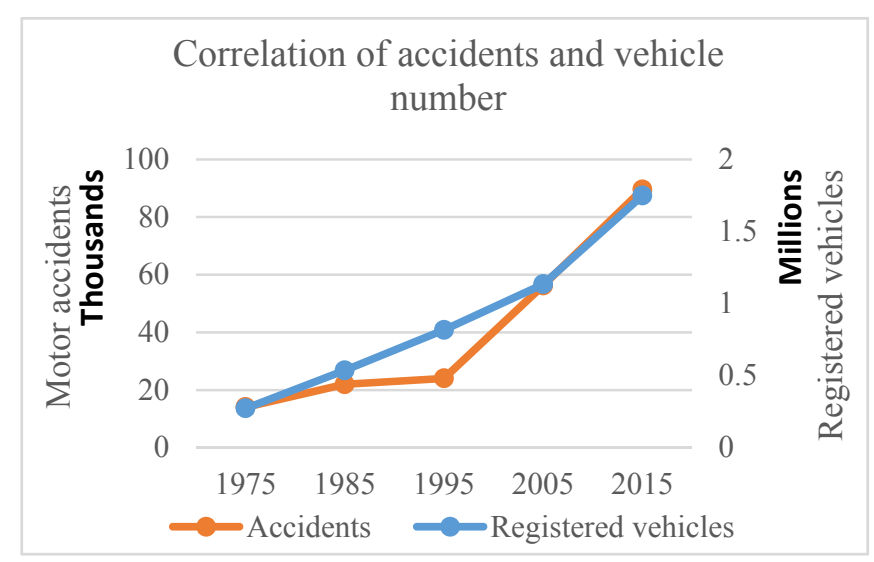

Figure 2. Motor accidents and registered vehicles correlation
In addition to congestion, housing availability is a major issue resulting from high urban density. Kuwaiti nationals are eligible for housing welfare support. In 1974 the National Housing Authority (NHA) - now the Public Authority for Housing Welfare (PAHW) was established as the authority responsible for housing welfare matters. Since its early years, NHA had trouble meeting the increased demand for housing. As early as 1980 - when a total of around 19,000 applications were submitted - the Kuwait government was no longer able to provide housing at the rate as in 2012; applications exceeded 100,000 according to Alshalfan (2013). Finally, the side effects of the development from Master Plans has put enormous strain on the Kuwait's environment as stated by Al-Damkhi et al., (2008).

\section{SIMULATION SCENARIOS AND AIMS}

Clearly, past urban expansion patterns in Kuwait resulted in a range of housing, congestion, and ecological issues. Land development constraints, including oil fields, nature reserves and military sites aggravate the problems, as the land use is not optimal. Alternative urban expansion methods must be considered to mitigate these negative effects. To that end, a bundle of simulation scenarios are proposed, which will be quantitatively compared to the base case scenario (existing urban expansion). The simulations are part of a three-year long research project. The three simulation scenarios of urban growth in Kuwait are:

1. Business as usual scenario of city centre expansion.

2. Master Plan 2030-2040 scenario.

3. Scenario implementing suggestions of citizens after interviews and surveys.

This paper describes in detail the first scenario. The scenario is intended to mimic historical growth by a simulation model, which develops an understanding of the main interactions between agents related to land use change in Kuwait. Throughout the simulations it is assumed that the current patterns of urban growth persist from 2015 to 2050. Following the trends set by the Master Plans, the simulated urban expansion scenario assumes low density expansion and high concentration of built environment in the CBD. Housing shortage and congestion are among the most severe issues in Kuwait and hence we attempt to both analyse the dimensions of these problems and envision their state within a horizon of 35 years. The proposed simulations will be carried out using Agent Based Modelling (ABM) models and GIS to account for population growth and land use patterns. The preliminary findings from analysing historical real data from Kuwait can be found in section 3.1. The findings from 3.1 were used as the main source of rules for the ABM design. Details about the model justification, design and parameterisation can be found in section 3.2. Additionally, there is an outline of the results and their usefulness.

\section{METHODOLOGY}

\subsection{Analysis of historical data}

Many of the assumptions used in the proposed model's design were derived from analysing the collected land use and demographics data. In this section, we will discuss the most important findings from the historical data and justify the development of ABM rules, which can be found in section 3.2

Urban development in general can occur via greenfield policies (developing new zones in previously undeveloped areas, such as desert) or intensification (developing new

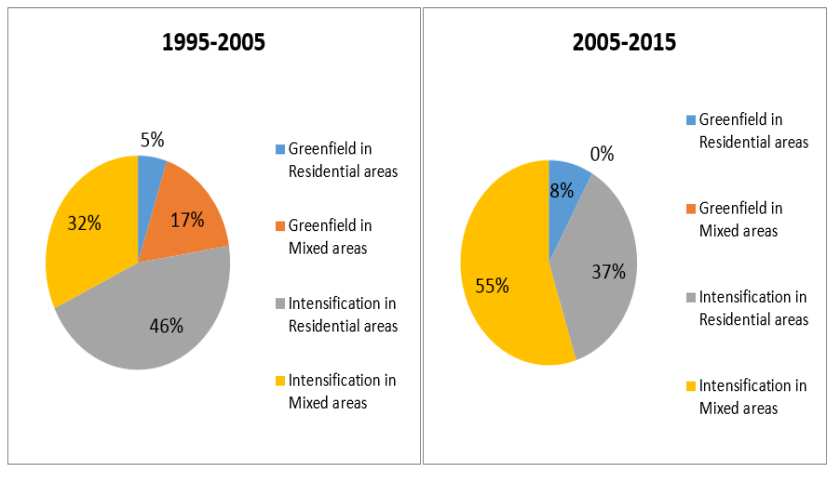

Figure 3. Comparison of greenfield and intensification development in Kuwait. 
zones within existing developed areas, such as infill or high-rise expansion). Figure 3 shows the ratio of greenfield and intensification development in Kuwait between 1995 and 2015. It can be seen that intensification is dominant. For intensification we found that $95 \%$ of the cases involved building in vacant land for both residential and mixed zones and only 5\% involved expanding or upgrading existing buildings. Another important finding was that for greenfield development, many more residential new areas were created compared to new mixed zone areas. The ratio we derived and will be used in the model is $80 \%$ residential and $20 \%$ mixed zone and an average of 9 new districts per decade. The average size of new greenfield zones was between $4.5 \mathrm{~km}^{2}$ and $5 \mathrm{~km}^{2}$ with an average of density of 4 Kuwaitis $/ \mathrm{km}^{2}$ and 3 NonKuwaitis $/ \mathrm{km}^{2}$ in residential districts and 2 Kuwaitis $/ \mathrm{km}^{2}$ and 20 Non-Kuwaitis $/ \mathrm{km}^{2}$ in Mixed districts.

In addition to using the assumption that these averages persist for the business as usual scenario until 2050, it was found that greenfield districts cannot be filled within a short period. Hence, most of the growth in greenfield is assumed to occur as intensification over the course of the years following its establishment. Regarding the distribution of nationalities, greenfield areas are populated by $45 \%$ Kuwaitis and $65 \%$ nonKuwaitis, while intensification areas are populated by $30 \%$ Kuwaitis and $70 \%$ non-Kuwaitis. The data showed that services such as supermarkets, schools, medical clinics, petrol stations are developed at the centre of each new district. For new mixed areas large shopping malls and universities act as cores of activity and development.

We also used real accident data to derive metrics for congestion. Using accidents data as an alternative to analyse and derive projections about congestion was necessary, due to traffic metrics such as the Vehicle Kilometres Travelled (VKT) and average speed not being used in Kuwait.

Based on the historical transportation data from 1995 to 2015 there were 0.5 cars per person and 0.02 accident per person in Kuwait. For each $1 \%$ of increase in registered vehicles yearly there is an associated $1.5 \%$ increase in accidents. Coupling this figure with historical data we can develop a set of projections for the future congestion patterns in the simulations.

To simulate the housing shortage impact, the average annual rate of change of applicants from Kuwaiti families to PAHW yearly was used (approximately $3 \%$ ). In addition, the average number of dwellings (house or land) offered by the government was calculated and found to be 2000 units per year.

According to Stevens et al. (2007) data about land use is necessary to better understand and simulate any situation of urban future expansion. The data preparation involved digitising and editing spatial data in ArcGIS to make it compatible for modelling. In order to design the simulation framework, Kuwait's districts were classified according to land use into residential, mixed use and other non-urban areas (industrial, agricultural, ports, desert). The resulting map can be seen in figure 4. Furthermore, the land was classified according to its development status into developed, developable in future, vacant land inside developed areas and land excluded from development. This classification was necessary for overlaying the data on the ABM model.
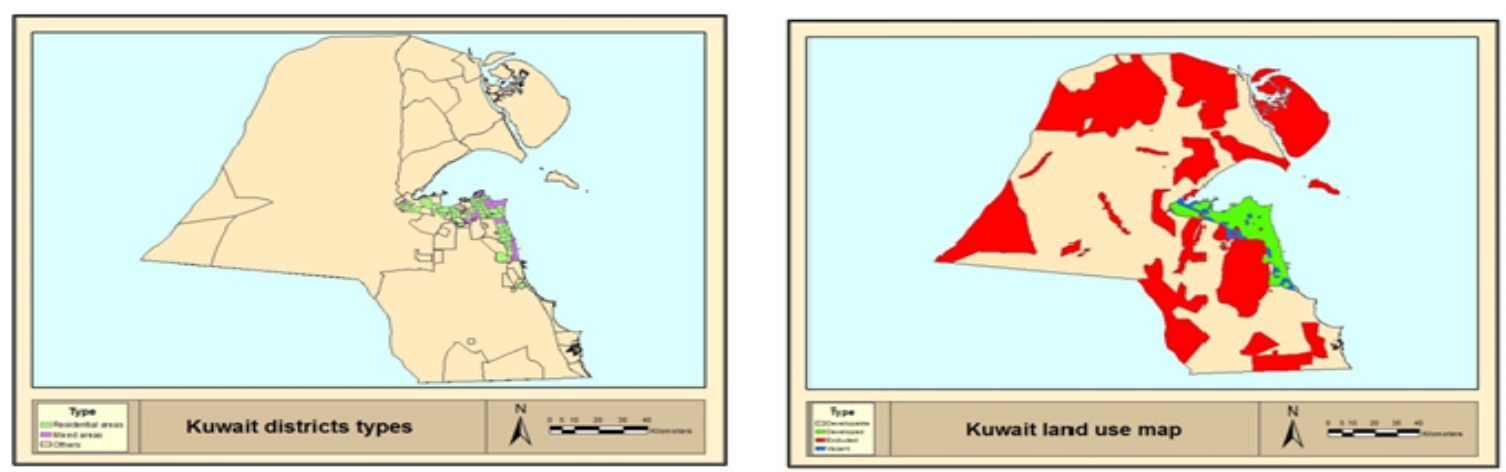

Figure 4. Classification of Kuwait's districts according to land use and development status. 


\subsection{Model design}

ABM has been suggested as a suitable model for urban dynamics by Brundson and Singleton (2015) as it is able to model the autonomous behaviour of agents involved in urban planning, and account for heterogeneous urban properties and population activities. The selection of ABM for this project is justified as it is a method able to provide a means to evaluate decisions by different groups, as agents, based on their settlement patterns and interactions with future plans. The flexibility and inherent hierarchical operational principles of ABM have been identified in similar urban studies. Agents of high level (government), midlevel (developers) and low level (citizen groups) interact in quantifiable ways in ABM simulations according to Matthews (2007). Agent-environment interactions can also be modelled, for instance the effects of social norms and traditions on property selection as seen in the work of Valbuena et al. (2010). In our case study, $70 \%$ of the Kuwaitis prefer owning property, while $65 \%$ of the non-Kuwaitis prefer renting. The work discussed in this paper is based on relatively simple rules and arguably ABM may not be utilised in meaningful ways; however, in the context of the full project which includes two additional scenarios for the urban expansion in Kuwait with multiple interrelationships between agents and agents with environment, the selection of ABM makes more sense as a common modelling platform, especially due to its ability to integrate data from GIS and public surveys (Robinson et al., 2007).

There are four groups of agents in the model:

1. Kuwaitis, who prefer living in residential areas $(85 \%)$, can own land $(70 \%)$, flats or houses, are eligible for PAHW grants and until they receive the grant or best offer have the option to temporarily live in family home, i.e. as extended families. In addition, the driving forces of their behaviours are economic opportunities offered by the government, and traditional family cultures.

2. Non-Kuwaitis, who usually rent a flat or house preferably in mixed areas $(65 \%)$, because they cannot possess their own real estate due to the Kuwait government rules.

3. The Kuwait government and planning authorities that has the power to open up new areas for greenfield development for residential and mixed areas. Its motivations for opening up new areas are not clear and needs to be better defined from future field work.

4. The developers, who are Kuwaitis with enough wealth and power to build houses, units, universities and shopping centres in the mixed districts as activity centres. They interact with the government to influence decisions that allows building new mixed areas.

The model simulates changes in urban form of Kuwait yearly until 2050 through land use changes driven by population growth, and behaviours/interactions by the four agent groups. Hence, it will run for 35 iterations, representing each year between 2015 and 2050, with the outputs being saved every 5 ticks. Choosing the new districts for development will be random, but with a set of rules to represent the reality. A group of people as variables will be represented in the new districts and their distribution will match the current average ratios of population (Kuwaitis and non-Kuwaitis) for each type of districts (residential or mixed) by using ArcGIS tools for the outputs. The main external factor of the model is the population growth. Population growth patterns based on historical data are discussed in details in section 3.1.

After analysing current and historical land use and demographic data, it was possible to define the set of rules that govern growth via urban intensification and greenfield expansion in an ABM model. The rules include:

- The developed areas must be filled until their capacity reaches the maximum accepted population capacity (average density based on nationality) for both land types (residential and mixed).

- Only the developable areas can be developed in greenfield process

- New developed areas have to be formed adjacent to the existing developed areas.

- New developed areas have to be formed as close as possible to the transportation network.

- New developed areas have to be formed as close to CBD and coast line as possible.

- New developed areas have to be formed as close as possible to service areas (ministries, companies, universities, shopping centres, hospitals, etc.).

- The new residential and mixed districts are created separately with sizes of 5 square km (based on averages from historical data).

The proposed model algorithm steps are as follows:

1. Initialise the model by loading input data and copying the original data:

a. Load the KISR population projections for Kuwaitis and Non-Kuwaitis. 
b. Load the existing land use feature classes.

2. Pass the greenfield model step.

3. Pass the Intensification model step.

4. Check if the year 2050 has been reached in the simulation after saving the outputs each 5ticks.

5. Add the yearly average rate of change of both accidents and PAHW applications.

6. Update the display with the output map and save the outputs.

The model outputs, once complete will allow us to quantify the problems arising from the continued expansion based on the business as usual scenario. The evaluation of the future state of housing availability will be done by calculating the number of housing units that will be available in relation to the population growth. Furthermore, current congestion data will be compared with the congestion projections from the simulations based on land use and population distribution and growth.

\section{RESULTS AND CONCLUSIONS}

The analysis of historical Kuwait data showed several clear trends in regards to the development of new land in Kuwait, as well as the demographics preferences and behaviour patterns for commuting and residential choices. While the findings from the analysis are undoubtedly interesting, the main purpose was to generate a set of rules to use for the proposed ABM model.

The agents of the model will operate under the rules described earlier and will allow simulations with outputs for the future:

- Land use distribution and growth based on the government agent behaviour.

- Population distribution for both Kuwaitis and Non Kuwaitis agents.

- Impacts of continuing with the current situation on housing shortage.

- Impacts of continuing with the current situation on congestion.

Preliminary results suggest that the continuation of the same urban expansion planning for the next 35 years will aggravate the problems of housing shortage and congestion (figure 5). Accidents will reach almost 140,000 , with a respective congestion increase. Housing shortage will continue and PAHW applications will reach almost 180,000 applications in the waiting list in 2050 . However, the validation of the results will be the topic of future work after the model has been implemented and the simulation results analysed.
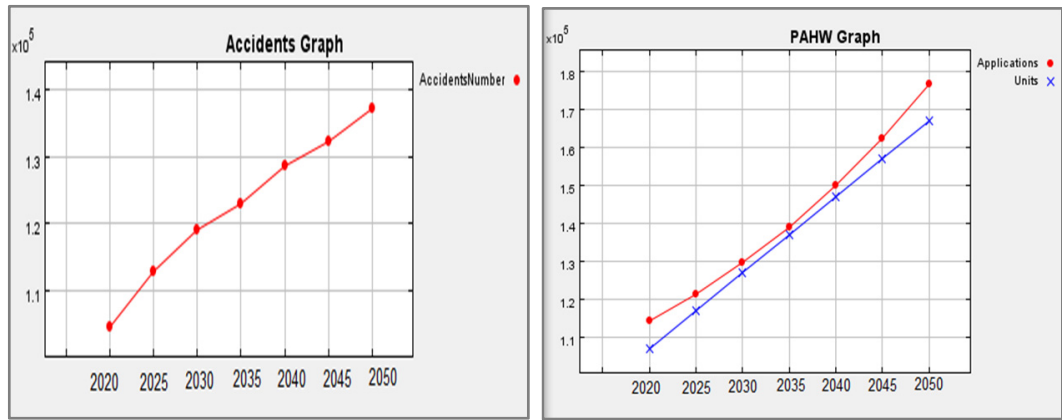

Another set of preliminary results provided some insight about the land use distribution. As seen in figure 6, 25 new districts (residential and mixed) were developed after the greenfield process. Figure 6 shows the comparison of the projected 2050 Kuwait zones with the current 2015 zones.

Figure 6. Projections about accident rate and housing coverage to 2050.
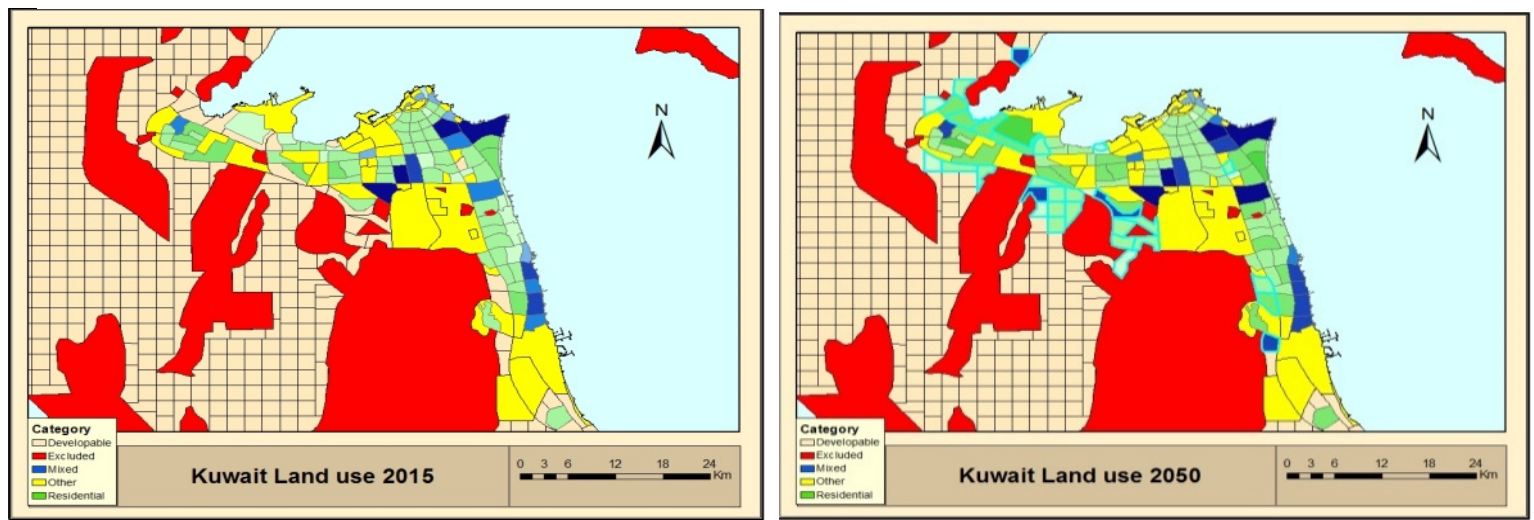

Figure 5: Comparison of current land use with projected land use from business as usual scenario in 2050. 
The analysis of the outputs will allow the investigation of the ways that changes in urban form from and policy decisions affect housing availability and congestion. Additionally, the findings may assist with research on the inherent correlations between urban form expansion and urban transportation quality, as well as land use distribution - not just in Kuwait, but in other modern cities especially ones that experienced rapid radial growth around their $\mathrm{CBD}$. With the results of the ABM simulations in hand, it will be possible to propose changes in the current approach of centre-focused urban expansion to alternatives such as a multinucleated urban form through public expression in the urban planning process. We believe that among the most important requirements for alleviating the negative future impacts is indeed involving the public suggestions in planning. Future work will attempt to simulate that alternative scenario based on surveying a stratified sample and comparing the outputs of both scenarios in the context of Kuwait future urban form.

\section{REFERENCES}

Al-Damkhi, A. M., Khuraibet, A. M., Al-Attar, F. A.-H., \& Abdul-Wahab, S. A. (2008). Integrating Environmental Impact Assessment within Kuwait Master Plans as a Tool for Human and Ecological Risk Control. Human and Ecological Risk Assessment: An International Journal, 14(5), 1070-1085. doi: $10.1080 / 10807030802387846$

Al-Nakib, F. (2013). Kuwait's Modern Spectacle: Oil Wealth and the Making of a New Capital City, 195090. Comparative Studies of South Asia, Africa and the Middle East, 33(1), 7-25.

Al-Nakib, F. (2014). Towards an Urban Alternative for Kuwait: Protests and Public Participation. Built Environment, 40(1), 101-117.

Alshalfan, S. (2013). The right to housing in Kuwait: An urban injustice in a socially just system (Vol. 28). London: London School of Economics and Political Science.

Belkina, T. D. (2014). From strategic urban planning to strategic urban management: Problems and solutions. Studies on Russian Economic Development, 25(6), 573-580. doi: 10.1134/S1075700714060033

Brunsdon, C., \& Singleton, A. (2015). Agent-based modelling and geographical information systems Geocomputation: A practical primer (pp. 63-77). Los Angeles: SAGE Publications.

Contin, A., Paolini, P., \& Salerno, R. (2014). Innovative technologies in urban mapping: built space and mental space. New York: Springer.

Ehrlich, R. S., Michael. (2003). The relationship between congestion levels and accidents. Maryland: University of Maryland.

Hamouche, M. B. (2004). The changing morphology of the gulf cities in the age of globalisation: the case of Bahrain. Habitat International, 28(4), 521-540. doi: http://dx.doi.org/10.1016/j.habitatint.2003.10.006

KuwaitCentralStatisticalBureau. (2012). Annual statistical Bulletin of transport. Retrieved 22 October 2014, from http://www.csb.gov.kw/Socan_Statistic_EN.aspx?ID=41

Matthews, R., Gilbert, N., Roach, A., Polhill, J. G., \& Gotts, N. (2007). Agent-based land-use models: a review of applications. Landscape Ecology, 22(10), 1447-1459. doi: 10.1007/s10980-007-9135-1

Robinson, D. T., Brown, D. G., Parker, D. C., Schreinemachers, P., Janssen, M. A., Huigen, M., . . Barnaud, C. (2007). Comparison of empirical methods for building agent-based models in land use science. Journal of Land Use Science, 2(1), 31-55. doi: 10.1080/17474230701201349

Ruming, K. J. (2014). Urban consolidation, strategic planning and community opposition in Sydney, Australia: Unpacking policy knowledge and public perceptions. Land Use Policy, 39(0), 254-265. doi: http://dx.doi.org/10.1016/j.landusepol.2014.02.010

Stevens, D., Dragisevic, S., \& Rothley, K. (2007). iCity: A GIS-CA modelling tool for urban planning and decision making. Environmental Modelling \& Software, 22, 761-773.

UNDP. (2009). National Traffic \& Transport Sector Strategy for Kuwait 2009-2019 Retrieved from http://www.kw.undp.org/content/dam/kuwait/documents/projectdocuments/Human\%20Developmen t/General\%20Directorate\%20of\%20Traffic\%20Project\%202009-2013\%20SIGNED.pdf

United Nations, D. o. E. a. S. A. (2015). World population prospects: The 2012 Revision. Retrieved 29th July 2015, 2015, from http://esa.un.org/unpd/wpp/index.htm

Valbuena, D., Verburg, P., Bregt, A., \& Ligtenberg, A. (2010). An agent-based approach to model land-use change at a regional scale. Landscape Ecology, 25(2), 185-199. doi: 10.1007/s10980-009-9380-6 